\title{
Forestry and Forest Wildlife A Conference Overview
}

\author{
by
}

\author{
Ian McTaggart-Cowan ${ }^{1}$
}

We came here under the command of four objectives, each of which arose from the assumption that joint integrated planning for the use of forest for timber production and wildlife would lead to a better contribution to Canada than would single-goal planning. This assumptioin is not yet totally acceptable to all those interested and concerned. Nonetheless our objectives have been:

1. To promote the integration of forestry and wildlife management in Canada on forest land.

2. To review existing policies and programs.

3. To recommend initiatives for improvement to land management agencies.

4. To promote professional and public awareness of the strengths and weaknesses of current management systems and concepts.

I shall not attempt to review each of the papers we have heard over the last three days. Rather, I shall assemble from them, from the discussions we have had, and from my own experience, some more detailed definition of our goals; some of the circumstances that have been preventing us from achieving them; and some of the most important modifications required to improve the rate of our progress.

This has been a conference on forests, forest harvests, and the productive manipulation of forests to maintain or increase wildlife. While focusing upon this important area, we must remember also that a large part of the Canadian biota inhabits prairie grassland, alpine and subalpine ecosystems, grassland ecotones, great basin shrublands, tundra and frigideserts. The rather limited roster of wildlife biologists has concern for all these as well as the extensive areas of commercial forest land.

We must recognize also that, intrinsic to our main theme, much of the forest biota finds its preferred habitat in mature forests, frequently forests of very specific characteristics.

We are aware also that deforestation, in some forests at least, influences not only the vegetation and its dependent biota directly, but has many indirect effects via soil movement, altered thermal regimes, snow depth, stream flows, and so on, which themselves influence the animal inhabitants. With these caveats let us get at the main theme.

In his thought-provoking introduction, John Livingston set the philosophical stage by reminding us of assumed truths that we seldom question: 1) the almost world wide concept of reality that modern technological/industrial man is in charge here and that his primary mission is to use all possible means

Prof. Emeritus, University of British Columbia, 3919 Woodhaven Terrace, Victoria, BC V8N is7 to extend his influence over the entire planet; 2) man is seen as having an unchallengeable right of proprietorship over the nonhuman elements of the planet; and 3) management seems to have become an imperative, not a means to a carefully defined end.

"The reality shared across technologically oriented societies is that technological development is progressive, its opposite is primitive, and destructive of the human purpose...."

That the attitude is alive and well could not have been better exemplified than in the emphatic statement by Ward Thomas that,

We are going to bring, over the next 50 years or so, most of the forest land of any commercial value that is not dedicated to other purposes, such as wilderness, parks, or refuges, into a managed state. We are going to complete the process of readying those forests for the long-term production of forest products, including wood and wildlife for the benefit of Homo sapiens.

$\mathrm{He}$ invited us to join in the great adventure. We enjoyed his thoughts and enthusiasm even though some of us here, and an increasingly large body of those outside the forestry profession, reject the mission.

Livingston averred that the goal of total domestication of the planet was not acceptable to him. Rosemary Fox agreed with him and was direct and emphatic. "What I am opposed to is the basic assumption underlying the dominant forces in our civilization that other forms of life exist ... solely for our own use...."

Armson was equally emphatic,

Many foresters and biologists approach management on the basis that if it exists - a spruce forest or deer land - it must be managed. Nothing can be farther from reality. Management objectives and decisions are ultimately economic and political

the degree of input and level of intensity and sophistication of activity must relate to ultimate benefits.

Unfortunately, we do not have the capability in either forestry or wildlife to establish priorities on the basis of objectives and anticipated returns.

Livingston went further to suggest there was a case to be made for defining a preferable goal to lighten the hand of man in the affairs of natural communities.

\section{The Objective of Integrated Management}

In light of the refinement of definitions urged upon us this morning by Baskerville, some of the terminology I have drawn from earlier speakers may be imprecise. That said, it appears that what we are attempting is to incrase the acceptance and implementation of silvicultural practices and management regimes that will have the effect of producing a greater net 
contribution from managed forest land to the broad spectrum of users.

Armson, Gayle, Innes, Salwasser, and Demarchi stated directly or by implication that areas of commercial forest should be managed to optimize the production of most forms of use: forest harvest, hunting and viewing of wildlife, and wild land recreation.

"In the Canadian scene two facts emerge clearly. The first is that management of our wildlife for the most part involves some form of manipulation of forest cover. The second is that the only user-group with either the interest in or the capability for such manipulation on any significant scale is the forest industry" (Armson).

This statement needs to be qualified in terms of forest wildlife and only those species that prosper in a managed forest.

Armson's view is reinforced by Demarchi,

As a wild life biologist, I can set hunting seasons and bag limits. In other words, I can manage the population, but the manipulation of habitat is in the hands of the forestry establishment. Thus the forester has more impact on wildlife circumstances than does the wildlife biologist.

I can echo this for grasslands and agricultural lands in substitution terms.

If these are the givens, surely it is the path of wisdom for the wildlife biologist enthusiastically to seek opportunities to participate in the design of forest management and silvicultural plans that will see his concepts and goals considered. But it is not as simple as that.

Where the objective of attaining the optimum mix of two or more resources on a given area prevails, the decision-making becomes much more complicated, as do the data requirements.

Salwasser states "The central problem in integrating wildlife and timber purposes in managed forests is to sift from all the natural complexity those few things that are useful, if not essential, in controlling forest for multiple forest goals'.

The adaptive management strategy promoted by Baskerville further emphasizes the problems. There is no gainsaying his argument that if you don't know what you are trying to achieve, in quantitative and detailed terms, and don't follow through with sensitive measurements of what happened as a result of your intervention, you are unlikely to learn anything.

Bunnell with his usual skill and élan outlined the successful attempt by himself and his students and associates over 6 years or so to provide the input data on a single question along the terms specified by Baskerville. This may be one of the first successful examples in the northwest coast region of Canada of integrated planning and forest management specifically designed to achieve a defined wildlife objective. We can use success stories.

Although the logic of our goal of integrating the objectives of wildlife management with forest management has been accepted, we have been reminded of a number of impediments.

Irving Fox put it this way: "In speaking about integrated resource use ... our concern lies with situations where a coordinated arrangement for two or more resource uses (on the same land area) will produce greater net benefits to society as a whole than if each is planned and undertaken independently ....." If the user groups are different and if the coordination results in one or more of these groups getting less benefit than through single resource use, then there can be a problem.

Where the individuals involved have quite different interests and values, it is not an easy task to achieve agreement on the pattern of resource use that will provide the greatest overall benefit to society.
Fox referred also to the problem of reaching judgments on allocation that can be perceived to be unbiased, and he provided a useful set of criteria which, though objective, will be viewed as idealistic by some of those charged with making decisions on allocation. His three criteria for reaching decisions that will be accepted as unbiased are: 1) no individual resource use should have preferred status; 2) all government agencies and nongovernmental interested parties should be able to participate on a basis of equality; and 3 ) no single organization, public or private, should be able to manipulate the process to its own advantage. He summarizes his findings, "My conclusion is that in British Columbia we have a long way to go to develop processes of integration that will provide a reasonable approximation of socially optimal allocation of publicly-owned resources among competing users."

\section{Requirements for More Effective Integration of Forestry and Wildlife on Forest Land}

Salwasser states that integrating wildlife habitat concerns into multiple-use forest management requires four things: 1) the right attitude, 2) a process for systematic resource coordination, 3) models that relate forest conditions to wildlife outputs, and 4) the effective use of monitoring to support an adaptive management strategy. Others emphasized the first of these, the will to accomplish the process, as paramount. Gayle properly stated that if the government agencies themselves are not integrated, the only way successful integration can be achieved is by giving the user responsibility.

Gayle used the term forest user, I think, as synonymous with timber extractor. Simply stated, the timber user needs "A continuous and sustained supply of wood of a consistent quyality at a constant real cost."

In Canada today we were informed that this essential need is being impaired by failure to restock denuded land, and the reduction of the forest land base. I infer from this that many foresters feel that they already have serious problems in meeting their first essential without having to introduce allocation for special wildlife needs. And yet some are already doing this.

Innes takes a further step in defining more precisely what he must know before he can begin integrating wild life into a forest management program. I will not attempt to repeat here his most useful summary and explanation but refer you to his paper.

I now come to the point of asking how do we get to where we want to be? Here, I want to emphasize that, despite all the impediments to achieving joint planning and implementation for both timber and wild life on forest land, it is happening, and it has broad consequences to a wide variety of wildlife species, small as well as large. Here and there in Canada people are making it work. I am informed that there are such success stories in Ontario and Manitoba. In British Columbia real advances are being made in the lands being logged by Crestbrook Logging in the east Kootenay area and also on the Belco land. Bunnell has found similar cooperation on northern Vancouver Island. I urge you to read his paper. You won't find a better, easier-reading case history. In each instance, the key to success is people and their dedication to making the integration work.

So, though we have had many suggestions as to ideal or more nearly ideal conditions to facilitate approaching our objectives, none of them are in sine qua non position. Let me summarize these required conditions:

1. An appropriate legislative framework. Armson says "Existing legislation tends to run counter to a need to move toward improved integrated management." I don't know whether this applies widely throughout the provinces.

2. Commitment. All of the parties must recognize and accept the wildlife management objectives - this will not be easy 
to achieve - for example the numerical objectives in the British Columbia wildlife plan are not acceptable to large groups of organized naturalists.

3. A planning process that encourages integration. This will include a willingness on the part of the wildlife biologist to put in the substantial amount of time required to participate fully with his forestry colleague in the development of a forest management plan.

4. A dedication by each to become as familiar as possible with the practical problems and objectives of the other.

5. An appropriate organization within the civil service. We have been told that integration of both foresters and wildlife biologists within a single ministry is essential. Perhaps so, but there are problems with the perceived consequences of this. Foresters in government are reaping the results of earlier years of inappropriate handling of the forest resource and the consequent distrust of people interested in aspects of the forest other than wood products. Fox has referred to the problem of convincing the public that forest interests will not automatically override wildlife interests. On the other hand there are provinces in which this form of administrative organization is successful.

6. "Provide the forest company with a form of assured tenure and along with this the responsibility (and accountability) to manage. To be successful there must be a firm commitment by the user to manage forests for cropping - the harvest of wood fibre, the harvest of fish and wildlife, and the "harvest" of recreational values, for a long-term sustained yield" (Gayle). In discussion it was suggested that private ownership of forest land and wildlife provides another successful model. However, difficulties were acknowledged because of the North American philosophical position on wildlife ownership.

7. Appropriate funding arrangements. It is suggested to us that costs of basic and intensive management must be regarded as an operating cost and provision made for funding on a long-term basis; not only management in a silviculture sense, but enhancement of wild life, fish, recreation, and water quality must all be funded before the government takes the surplus income as stumpage.

It has been suggested to me that there are opportunities to bring forestry management practices at the government level up to date with new developments, and that these will permit the reallocation of large sums of money to the integrated management program.

But most of these prescriptions are essentially technological and managerial and in bringing my overview to a close I want to reemphasize that despite all the structural and admi- nistrative shortcomings of the environment in which we strive, there are successes to report and these are likely to be more important than they seem. They are lighthouses along the way to our destination. And without exception, they reflect the activities of unusual people who can transmit their enthusiasm to others, elicit mutual respect, and have the needed skills in research.

I want to thank Fred Bunnell most sincerely for two more contributions that have lightened my task. First, he did not read us his prepared paper, and second he gave me a copy of it. Accordingly, I will close my remarks with a Bunnellian quotation which I am sure will lead you to his paper. I quote from his admonition to forest managers: Be tender with the academician: the ivory tower is sometimes real, the aphorism "publish or perish" always is. Academicians need time to write as well as to pursue facts. The astute manager can exploit a researcher's best guesses through jointly-designed adaptive management. Both should benefit. However, the manager should then be aware that the researcher (potentially terrified by exposing an unpublishable best guess), may demand that the manager publicly confess that he too does not know exactly what he is doing. Although superficially denying knowledge, such behaviour appears to have advantages. It frees the manager from any myth of omniscience and may actually increase his credibility. The frank admission of limitations to knowledge is especially applicable to the wildlife manager. Because animals can think and move faster than trees, the wildlife manager's world will always contain more surprises than the forester's world.

In these three days we have taken a further important step toward our objectives. I am optimistic that, with increased understanding and dedication, there will be a tide of success stories ahead.

One further admonition to both of the cooperating parties. There is a broad and growing body of interested citizens beyond your office walls. The day is past when you can ignore them as you plan and manage public resources. They are not yet fully convinved that what you are seeking will best serve their wishes. Those working with wildlife are more comfortable than most foresters in being frank and open with the public, but are often not very imaginative. There is change of attitude required and I don't mean hiring more public relations workers. The broad philosophical difference emphasized earlier in my review is real and the number of individuals who do not accept the purely economic view of forested lands is growing. It is important that more attention be given to accommodating the legitimate interests of the naturalist, and wilderness seeker in overall plans for forest land. 